\title{
How Judgments of Visual Resemblance are Induced by Visual Experience
}

\author{
Alon Chasid, Philosophy Department, Bar-Ilan University
}

Alik Pelman, Technion - Israel Institute of Technology; Shenkar College of Engineering, Design \& Art

This is a penultimate draft. The final version is forthcoming in the Journal of Consciousness Studies. Please cite the published version only.

\begin{abstract}
Judgments of visual resemblance ('A looks like B'), unlike other judgments of resemblance, are often induced directly by visual experience. What is the nature of this experience? We argue that the visual experience that prompts a subject looking at A to judge that A looks like B is a visual experience of B. After elucidating this thesis, we defend it, using the 'phenomenal contrast' method. Comparing our account to competing accounts, we show that the phenomenal contrast between a visual experience that induces the judgment that A looks like B, and a visual experience that does not induce this judgment, is best explained by the fact that the former visually represents B, whereas the latter does not.
\end{abstract}

Keywords: resemblance; judgments of resemblance; visual resemblance; phenomenal contrast.

\section{Introduction: the core thesis}


The notion of resemblance is invoked in a wide variety of contexts. We say, for instance, that one theory or idea is similar to another theory or idea; that the educational system in one country resembles that of another country; that two individuals are alike in character; and so on. This paper focuses on visual resemblance, i.e., the sort of resemblance we usually refer to by saying that one object looks like another object. For instance, looking at John, Mary claims that he looks like his father; looking at a monkey orchid, Carlyle claims that it looks like a monkey; looking at blood vessels, Leo claims that they look like tree branches; etc. ${ }^{1}$

Judgments of visual resemblance (henceforth: JVRs), unlike other judgments of resemblance, often ensue directly from visual experience. This fact can be illustrated by a scenario where we go from not having a specific sort of visual experience to having it. Suppose, e.g., that Mary and her friends debate whether John looks like his father, Jim. While

\footnotetext{
${ }^{1}$ Another type of example is related to pictorial experience, i.e., the visual experience we ordinarily have when looking at a picture. In looking at a picture of, say, a horse, we often claim that the markings on the picture's surface visually resemble a horse. Robert Hopkins, for instance, famously argued that pictorial experience, or "seeing-in," is the experience of these markings as resembling the depicted object in outline shape (Hopkins 1998, 77). Other interpretations of this claim have been suggested; for an overview, see Hyman and Bantinaki (2017); Kulvicki (2014, ch. 3). Yet to our knowledge, neither Hopkins nor other philosophers analyze the notion of visual resemblance, they simply invoke it to account for pictorial experience. As our account does analyze visual resemblance, it obviously has implications for theories of depiction, especially those that invoke resemblance. However, we will not discuss this issue here: given the many theories of depiction, pictorial experience, and the 'twofold' structure of pictorial experience, applying our account to these theories would exceed the scope of this paper, and must be addressed separately.
} 
Mary is looking at, and visually experiencing, John, Mary's friends encourage her to note the visual similarity between John and Jim, drawing her attention to specific aspects of John's face. Attending to these aspects, Mary admits that John shares them with Jim, but denies that John looks like Jim, saying something like: “I agree that John's nose, jawline, and eyebrows have the same shape as his father's nose, jawline, and eyebrows, but as to John's face, I don't take it to look like his father's face."

At a certain point, however, Mary visually experiences something that prompts her to judge that John looks like Jim. To recognize that John looks like Jim, she no longer needs to rely on her friends' reports, or (consciously) assess the number and structure of properties John shares with Jim, for she now 'sees' what her friends were encouraging her to see. The judgment that John looks like Jim ensues directly from her visual experience.

The latter kind of visual experience - the kind of experience that prompts Mary to judge that John looks like his father Jim - is the focus of this paper. Of course, one can have this kind of experience, viz., an experience that straightforwardly evokes a JVR, immediately upon looking at an object, i.e., without going through an experiential shift as Mary did. Whether or not such a shift occurs, what is crucial for our argument is the phenomenal contrast exemplified by Mary's experiential shift, namely, the contrast between a visual experience that doesn't prompt us to make a JVR, and a visual experience that does prompt us to make to make a JVR.

Utilizing the abductive 'phenomenal contrast' method (Siegel 2007; 2010), we will defend the thesis that the phenomenal contrast between a visual experience that doesn't prompt the JVR that A looks like B, and one that does, is best explained by the fact that although both experiences are generated by looking at A, the JVR-prompting experience represents B, whereas the non-JVR-prompting experience does not represent B. Mary, e.g., is prompted to make the JVR that John looks like Jim because in looking at John (A), at some 
point her visual experience shifts, at least momentarily, from representing John to representing $\operatorname{Jim}(\mathrm{B})$.

We obviously accept the claim that the shift from visually experiencing John to visually experiencing Jim requires that Mary visually attend to a specific set of John's visible properties, namely, those that are associated with Jim's appearance. In arguing that the JVR that A looks like B is prompted by the visual experience of B, we aren't claiming that the experience of B arises 'just like that,' in some magical way, without attention having been paid to visual cues associated with B. Our point is that such visual attentiveness alone is insufficient to induce the JVR in question, as the case of Mary demonstrates. Recall that although Mary is attentive to properties that John shares with Jim, she initially denies that John looks like Jim. We will argue that, assuming that the experiencer is visually attentive to properties A shares with B, the visual experience that prompts the JVR that A looks like B is a visual experience of $B$, who is indeed experienced as having those properties. (A complication arising from this claim is addressed in §2).

It is important to note that the JVR that A looks like B need not be made on the basis of the visual experience in question, viz., an experience that represents B. The judging subject could also accept reliable reports asserting that A looks like B ('everyone I trust says that A looks like B'), infer that the sort of visual experience in question would arise under normal circumstances, rely on some scientific mechanism or algorithm that detects visual resemblance, etc. This paper, however, focuses on JVRs that are prompted straightforwardly by visual experiences. That JVRs sometimes ensue straightforwardly from visual experience, as in the case of Mary's JVR, is thus the minimal assumption required for our argument to get off the ground. Our goal is to account for such JVRs in terms of the type of visual experience that prompts them. 
The fact that JVRs are often prompted by visual experiences implies that JVRs differ, at least in this respect, from other judgments of resemblance. Indeed, to say that A resembles B in non-visual respects is often to say no more than that A shares certain properties with B. Despite the reservations about judgments of resemblance spelled out in Goodman (1972), we accept the claim that such judgments are a common occurrence. Nor do we dismiss the plausibility of metaphysical accounts of resemblance that take such judgments to be based on shared properties and calculations thereof, e.g., the account proposed by Blumson (2017). We contend, however, that judgments of visual resemblance differ from other judgments of resemblance in that they can ensue from visual experience. ${ }^{2}$ What initially keeps Mary from making the JVR that John looks like Jim is not that she hasn't consciously assessed the number of visual properties John shares with Jim, or the structure of these properties, the relations between them, etc. However visual properties (i.e., properties represented in visual experience) are individuated, to make the JVR, neither Mary nor her friends need be aware of this individuation, let alone make conscious computations about how many properties are shared. Rather, their JVRs ensue directly from their visual experiences. Hence the key to explaining why JVRs are made in such cases is to analyze these JVR-prompting experiences.

Two prefatory comments are in order. First, although our account is compatible with any theory of perception, for convenience, we will formulate it in representationalist terms. We

\footnotetext{
${ }^{2}$ Note that the differences between judgments of visual resemblance and judgments of nonvisual resemblance do not entail that visual resemblance and non-visual resemblance are two different notions; rather, resemblance is a notion that applies in various ways, the differences between which may not be explicit. As Armstrong (1978, 98-99) points out, the subject may not be aware of the specific respect with regard to which she is making a judgment of resemblance. We thank an anonymous referee for pointing this out.
} 
will take visual experiences to be mental representational states, i.e., states that represent objects as having certain properties. We will likewise assume that the content of visual experience is propositional, and that experiences are either veridical or non-veridical by virtue of satisfying or failing to satisfy correctness conditions. Specifically, the claim that, in looking at A, one has a visual experience of $\mathrm{B}$, entails, according to many theories, ${ }^{3}$ that one has a non-veridical visual experience, namely, an 'incorrect' mental representation-a representation the propositional content of which is false. Furthermore, one can have a visual experience-i.e., a visual mental representation — without believing the visually-represented content, as happens when we are aware that our experience has false content, e.g., when aware of illusions or hallucinations. Representationalism, however, is no more than an expedient platform for our analysis, and the arguments we put forward can be adapted to fit other theories of perception.

The second comment pertains to general constraints on perceptual content. The account we propose is premised on the possibility of looking at object A and visually experiencing object B. This possibility presupposes that perceptual content can be singular (i.e., can refer to a particular object), and that it can refer to an object other than the object being looked at. These presuppositions are indeed plausible on a cluster of views termed "the internalist

\footnotetext{
${ }^{3}$ Since it is generally accepted that locations are represented in visual experience (see, e.g., Siegel 2016, §4), the kind of experience in question (looking at A and visually experiencing B) is non-veridical, if only because it represents B as located somewhere other than its actual location. There may be other reasons for deeming this experience non-veridical (e.g., if B does not exist, the experience is non-veridical). However, our account is also compatible with theories on which the said experience can be veridical (see, e.g., Walton 2008, ch. 6 on seeing through photographs).
} 
outlook" (Siegel 2010, 5-6), according to which the content of experience is determined 'internally,' ${ }^{4}$ and can refer to particular objects. However, some philosophers reject this 'internalist' outlook. ${ }^{5}$ On non-internalist views, it cannot be the case that one visually experiences B by looking at A, hence reports such as 'Mary is looking at John, but visually experiencing Jim,' cannot be taken literally. To accommodate non-internalist assumptions, instead of referring to a visual experience of B that is generated by looking at A, we must refer to a type of cognitive state (i.e., a belief or thought) that singularly represents B, a cognitive state that is characterized functionally as that which ensues directly from applying one's recognitional abilities to one's visual experiences, to the effect that the intentional object (in our case: B) is represented by this state. For convenience, we will frame our account in internalist terms.

We will now refine our account (§2), after which we will present our main argument for it (§3). Applying the method of phenomenal contrast, we will show that our account best explains the phenomenal difference between a visual experience that prompts a JVR and that which does not.

\section{Further clarification: awareness, indeterminacy, phenomenology}

Our core thesis is that, in the sort of cases under consideration, namely, cases where one looks at A and is prompted by one's visual experience to judge that A looks like B, the visual

\footnotetext{
4 'Internally'-determined content is usually the intentional content that accords with the perceiving subject's attitudes and behavior; see, e.g., Harman (1990).

${ }^{5}$ See, e.g., McGinn (1982, 39; cf. Tye 2009, §1); Crane and French (2017, §3.3.3); Siegel (2016, §5.1).
} 
experience that prompts the judgment that A looks like B is a visual experience of $B$. Another, perhaps trivial, condition is that the visual experience of B in such cases must not generate the belief that one is looking at B. More precisely, to judge (when looking at A) that A looks like $\mathrm{B}$, one must, despite having a visual experience of $\mathrm{B}$, be aware that one is looking at A. For obviously, someone who doesn't know or believe that she is looking at A, would presumably, upon looking at A and visually experiencing B, simply believe that she is looking at $\mathrm{B}$, and hence would not be induced to make the JVR in question.

A more crucial point pertains to the properties represented in the JVR-prompting experience. As mentioned in $\S 1$, we are not arguing that someone looking at A, and aware that she is doing so, 'magically' finds herself visually experiencing B. The experience of B must ensue from visual cues associated with $\mathrm{B}$, as experiences of $\mathrm{B}$ ordinarily do. This point requires further clarification, in light of the fact that when making the JVR that A looks like $\mathrm{B}$, one is often aware that, despite the visual similarity between A and B, B differs from A in various visual respects. Given such visual differences, and indeed, given that the overall set of visual properties is primarily associated with A and not with $\mathrm{B}$, how can one visually experience B by looking at A, as per our thesis?

In certain cases, this question does not arise, since it is easy to experience B by looking at A. For instance, if John is dressed up as Donald Trump, someone looking at John could easily find herself visually experiencing Trump. Knowing that she is looking at John, she might be induced to assert something like: "The makeup is perfect, John; you look exactly like Donald Trump!” In general, cases where A is dressed up to look very much like B (or where $\mathrm{A}$ is viewed under abnormal conditions that generate that effect, or where $\mathrm{A}$ and $\mathrm{B}$ have a natural physical resemblance, as in the case of identical twins, etc.), fit neatly with our account. Observing properties that are primarily associated with B's appearance, one can find 
oneself visually experiencing B, while knowing or believing that one is looking at A. In such cases, one is immediately prompted by this visual experience to judge that A looks like B.

However, such cases are uncommon. Ordinarily, A is not dressed up as B or viewed under abnormal conditions that render A's appearance B-like. In ordinary cases, the JVR that A looks like B is made despite readily-perceptible differences between A and B. In the case of Mary, for instance, John has his usual appearance, the visual differences between him and his father are manifest, he can hardly be mistaken for Jim, etc. Yet Mary (after her experiential 'shift') and her friends judge that John looks like Jim, which means, on our account, that in looking at John, they fleetingly visually experience Jim. But how can they visually experience Jim rather than John, given that the overall appearance of the person they're looking at is straightforwardly associated with John, and the differences between John and Jim are evident?

An initial response might invoke the notion of attentiveness. Mary and her friends attend to a subset of John's visual properties that are associated with Jim's appearance, and thus visually experience Jim. This response, however, is inadequate. To generate a visual experience of B, attentiveness to visual properties of A that are associated with B's appearance is necessary, but insufficient. For it is possible to be attentive to such properties without visually experiencing B (or being prompted to make the JVR in question). Recall that before the 'shift,' Mary was aware of the said properties (the shape of John's eyebrows, jawline, etc.), accepted her friends' claim that these specific properties were the same as Jim's, yet denied that John looked like Jim. Nevertheless, at some point Mary did shift to having a visual experience of Jim. This entails that, together with attentiveness to those of John's visible properties that are associated with Jim, another element was involved in generating Mary's visual experience of Jim. Moreover, mere attentiveness to properties John shares with Jim does not 'override' the evident differences between them. Without further 
explanation, it is unclear why visual cues straightforwardly associated with John but not with Jim do not impede Mary's visual experience, and she can shift, at least for a moment, to visually experiencing Jim. To generalize, we need to explain how the subject, in looking at A (under normal conditions), can ignore the visual aspects of A that are not associated with B's appearance, to the effect that she visually experiences B.

Examining the problem from a different perspective may prove edifying. Suppose, again, that despite the visual resemblance between $\mathrm{A}$ and $\mathrm{B}, \mathrm{A}$ is visually different from $\mathrm{B}$ : $\mathrm{A}$ and $\mathrm{B}$ have several patently different visual features, would not be mistaken for one another, etc. Suppose, further, that our thesis is correct: the JVR-prompting experience is an experience of B. The crucial point is that, given the manifest differences between $\mathrm{A}$ and $\mathrm{B}$, the phenomenology of the visual experience of B that is generated by looking at A differs significantly from the phenomenology of ordinary visual experiences of B. In the case of Mary, for instance, the visual experience of Jim that, we contend, prompts the judgment that John visually resembles him, is phenomenally different from ordinary visual experiences of Jim. Whatever properties Mary and her friends are attentive to when looking at John, the manifest visible differences between John and Jim render the ensuing visual experience of Jim phenomenally unique relative to the way Jim is visually experienced ordinarily. What explains this phenomenal uniqueness?

Our explanation invokes the fact that visual experiences are sometimes indeterminate in content. We claim that in cases where A, despite being visually different from B, is judged to look like $\mathrm{B}$, the experience of $\mathrm{B}$ that is generated by looking at $\mathrm{A}$ is an indeterminate experience of $\mathrm{B}$. That is, the properties that $\mathrm{B}$ is experienced as having are relatively unspecified, hence the experience of B is phenomenally different from ordinary experiences of B. Given the visual differences between John and Jim, the shift from experiencing John to experiencing Jim involves, in addition to attentiveness to properties A shares with B, a shift 
in the degree of determinacy of the represented properties. Upon shifting, Mary's visual experience 'adjusts' itself by ceasing to represent some of John's properties determinately, and representing properties associated with Jim's appearance indeterminately. The aberrant phenomenology of Mary's experience of Jim is thus explained by the fact that, in general, indeterminate visual experiences-namely, experiences that represent properties without fully specifying them-have an unusual phenomenology.

Let us explain this claim further. Our focus is cases where, despite visual similarity between A and B, they are also visually different. Furthermore, the overall visual appearance of the observed object (i.e., A) is primarily associated with A, not B. Our goal is to explain how, in these cases, the person looking at A can shift from experiencing A to experiencing B (and thus be prompted to judge that A looks like B). Since this sort of shift from experiencing one object to experiencing another is not magical, but (in the kind of case in question) involves a shift in the visually-represented properties, our explanation must invoke a shift of this sort. Familiar shifts in experienced properties occur, for instance, when an experience represents a coin as either circular and tilted, or-upon shifting - elliptical but not tilted. Likewise, an object may be represented as either white but shaded, or — upon shifting — as grey and normally illuminated. Other familiar sorts of experiential shifts are shifts in Gestalt (as in the classic duck/rabbit example), cases of binocular rivalry, etc.

However, these sorts of shifts—elliptical/circular shifts, Gestalt shifts, etc.-in the properties represented in visual experience do not suffice to explain the experiential shift in question. For in cases where the visual cues are primarily associated with $A$, we must explain how these cues can be ignored, so that $B$ is experienced instead of $A$, and why the phenomenology of the experience of $\mathrm{B}$ is unusual relative to ordinary experiences of $\mathrm{B}$. To do so, we have to invoke another sort of shift - the shift from experiencing properties determinately to experiencing them indeterminately. 
Perceptual indeterminacy is typically associated with blurred or hazy visual experiences, visual experiences under abnormal conditions (darkness, fog, etc.), distortion filters, and so on. In such cases, a visual experience may change from representing properties determinately to representing them indeterminately, and vice versa. For instance, one might look at an object and experience it determinately as being fuzzy, then, looking at the same object under the same conditions, have a different, indeterminate experience of it: an experience that does not demarcate the object's boundaries. ${ }^{6}$ In the first scenario, the experience prompts the belief that the object itself lacks definite boundaries; in the second, the experience prompts the belief that the object has definite boundaries, along with uncertainty about where, precisely, those boundaries fall. Looking at a poorly-illuminated object is another straightforward example of a determinacy / indeterminacy shift. Visual experience may represent the object determinately, as being black, or indeterminately, as having some unspecified dark hue. If the former is the case, the experience induces the belief that the object is black, if the latter, it induces the belief that the object has some dark hue.

In the case under discussion, when Mary first looks at John, she experiences John determinately. When Mary's experience shifts to representing Jim, the shift occurs not only due to her attentiveness to shared properties, but also due to a reduction in the determinacy of some represented properties, especially the properties that are associated with John. The 'dismissal' of various visual cues associated with John is, indeed, due to a shift in the degree of specification of these properties. Mary 'zooms out,' so to speak, rendering her visual experience indeterminate to a degree that suffices for the overall set of (relatively

\footnotetext{
${ }^{6}$ This example is from Tye (2002), but our argument is neutral vis-à-vis the debate in which Tye adduced the example.
} 
unspecified) properties to be associated with Jim's appearance, hence Jim is represented in Mary's experience.

The phenomenal discrepancy between ordinary experiences of Jim, and the experience of Jim that is generated by looking at John, is thus explained by the fact that Jim is represented indeterminately. As a rule, indeterminate experiences are phenomenally aberrant: the phenomenology of experiencing an object through fog or a filter that causes blurriness differs significantly from experiencing it under normal conditions. Mary can, obviously, have a determinate experience: she can have an ordinary experience of John, as she indeed had before the shift. But when Mary’s experience represents Jim, it represents Jim indeterminately, and is thus phenomenally unusual, just like the indeterminate experiences of objects seen through fog or haze, or under abnormal conditions.

To recapitulate, our core thesis is that, when someone looking at A is prompted by her visual experience to judge that A looks like B, this judgment ensues from a visual experience of $\mathrm{B}$. This experience is rendered possible because the visual differences between $\mathrm{A}$ and $\mathrm{B}$ are 'neutralized' by a reduction in the determinacy of the experienced properties, the import of this reduction being that the overall set of indeterminate properties is associated with B. Since the experience of B is relatively indeterminate, its phenomenology differs from the phenomenology of ordinary, determinate experiences of B.

Having explained our core thesis, we will now proceed to argue for it. Our argument is that the proposed account best explains the phenomenal difference between JVR-prompting experiences and non-JVR-prompting experiences. 


\section{The phenomenal contrast argument}

This paper seeks to defend the thesis that when someone looking at A judges that A looks like $\mathrm{B}$, the experience which prompts that JVR is an experience of $\mathrm{B}$ that is generated by looking at A. This thesis can be considered a hypothesis about the content of experience, specifically, the content of the JVR-prompting experience. A generally-accepted method for testing hypotheses about the content of experiences is the abductive phenomenal-contrast method (Siegel 2007; 2010, §3.3). ${ }^{7}$ The basic premise of this method is that to test a hypothesis about the content of an experience, we need to accept that there is a phenomenal contrast between an experience that exemplifies the hypothesis, and an experience that does not exemplify it. ${ }^{8}$ We then need to examine, by comparing our hypothesis to competing hypotheses, whether our hypothesis also best explains the phenomenal contrast; if it does, we can conclude that the hypothesis is correct.

Let us apply this method to our thesis about JVRs. Our starting point is the aforementioned contrast between an experience that induces one to make a JVR, and an

\footnotetext{
${ }^{7}$ A forerunner of this method was suggested by Siewert (1998, 255-62). Despite its overall acceptance, some reservations about the phenomenal-contrast method have been voiced (Chudnoff 2015, Koksvic 2015); cf. Helton (2016, 854-5), which addresses these reservations.

${ }^{8}$ That a particular phenomenal contrast obtains is a basic intuition: the argument does not work for those who do not accept it; see Siegel $(2010,101)$. In our case, the contrast is straightforward: to judge, in the cases in question, that A visually resembles B, one must be prompted by a visual experience. The pertinent contrast is therefore the contrast between a non-JVR-prompting visual experience, and a JVR-prompting visual experience.
} 
experience that does not. When Mary is first encouraged by her friends to acknowledge the visual resemblance between John and Jim, she responds by saying that, despite noticing some shared properties, she cannot, on the basis of her own experience, judge that John looks like Jim. Her experience then shifts, prompting her to make the JVR. There is thus a phenomenal contrast between Mary’s non-JVR-prompting visual experience and her JVR-prompting visual experience. Our thesis-i.e., that the JVR-prompting experience is an experience of Jim - is a plausible explanation of this phenomenal contrast between Mary's initial, nonJVR-prompting visual experience, and her JVR-prompting visual experience. We argue that the contrast is due to the fact that the former experience represents John whereas the latter represents Jim.

Schematically, this can be expressed as follows. In one case, the subject looks at A and is not prompted by her experience to judge that A looks like B; let 'E1' be this non-JVRprompting experience. In the other case, the subject looks at A and is prompted to make a JVR; let 'E2' be this JVR-prompting experience. Let 'PC' be the phenomenal contrast between E1 and E2. We propose that what explains PC is hypothesis $\mathrm{H}$ :

H: E1 represents A, and E2 represents B.

To show that $\mathrm{H}$ best explains $\mathrm{PC}$, we need to compare $\mathrm{H}$ to rival hypotheses. Following Siegel (2010, 91-96), we suggest three such alternatives, H1-3. The first is H1:

H1: E2, but not E1, involves a nonrepresentational feature, namely, a rawfeel. ${ }^{9}$

\footnotetext{
${ }^{9}$ Recall that we frame our argument in representationalist terms (see $\left.§ 1\right)$. Although representationalists generally deny that experiences can have nonrepresentational
} 
Whereas H explains PC by adducing a difference in the experiences' representational content, $\mathrm{H} 1$ denies that the experiences differ in their representational content. Rather, it explains PC by adducing a nonrepresentational property, a rawfeel, that E2 has and E1 lacks. Applied to our case, $\mathrm{H} 1$ contends that after Mary has been visually experiencing John for a while (E1), her experience allegedly changes in a nonrepresentational way, involving a rawfeel, inducing her to judge that John visually resembles Jim.

However, H1 seems to attribute excessive power to the hypothesized rawfeel. For how could a rawfeel induce one to make a JVR? If indeed Mary's experience has a nonrepresentational aspect, it is unlikely that it could induce her to judge that John looks like Jim, since it doesn't 'say' anything, let alone impart specific information about Jim. And conversely, if the rawfeel does convey something that induces Mary to make that JVR, then it seems to be representational after all, i.e., not a rawfeel. In the context of JVRs, rawfeels are ineffectual, hence $\mathrm{H} 1$ does not seem to be a satisfactory explanation of PC, let alone a better explanation than H. (For more general arguments against H1, see Siegel 2010, 109-110.)

Let us consider a second alternative explanation:

phenomenal features, we will consider H1 a plausible hypothesis (as Siegel 2010 does), since certain 'minimal' versions of representationalism do regard nonrepresentational phenomenal features as possible; see, e.g., Macpherson $(2014,372)$ and Fish $(2010,70)$. Our critique of H1 therefore rests on other concerns, concerns that are neutral vis-à-vis different versions of representationalism. 
H2: E2, but not E1, is accompanied by a phenomenally-conscious non-sensory (cognitive) state. $^{10}$

On this hypothesis, some sort of non-sensory (and, a fortiori, non-visual) phenomenology accompanies E2 but not E1, and this non-sensory phenomenology explains PC. Non-sensory phenomenology is the phenomenology of non-sensory mental states, for instance, being struck by a thought. According to H2, while Mary is looking at John, a change in, say, her thoughts or beliefs, gives rise to the non-sensory phenomenology that explains PC. Note that, although our assumption is that PC involves Mary's visual experience, $\mathrm{H} 2$ can still be deemed a possible explanation, since the phenomenal shift may not be in her visual experience itself, but rather in a cognitive state that straightforwardly ensues from her visual experience.

However, it is difficult to identify a thought or belief that can plausibly be associated with the phenomenal contrast we seek to explain. First, the mere thought that A looks like B would not suffice to explain PC. Mary, for instance, obviously entertains the thought that John looks like Jim, as well as related thoughts, before the phenomenal shift, when she is considering her friends' JVR, and for the purpose of testing its truth, assumes the truth of the proposition that John looks like Jim. This thought thus cannot explain the phenomenal contrast between E1 and E2, since it can accompany both experiences.

Second, the alleged cognitive state cannot be the belief that A looks like B. For like the thought just considered, this belief can be held by the subject before the phenomenal shift

\footnotetext{
${ }^{10}$ For the reasons given by Siegel $(2010,107 \mathrm{ff}$.), we reject the claim that the putative nonsensory contrast reflects a shift in the subject's background phenomenology, as opposed to a shift in an occurrent cognitive state.
} 
occurs, i.e., when she is having E1. Mary, for instance, can, while looking at John before the shift occurs, consider, and accept, her friends' opinion about the resemblance. Perhaps, convinced of her own cluelessness about visual similarities, she trusts their reports over what she herself sees. She can thus hold the belief that John looks like Jim by virtue of testimonial evidence, without experiencing any phenomenal shift.

If, in taking PC to be non-sensory, supporters of $\mathrm{H} 2$ invoke a belief, this belief must, on the one hand, be straightforwardly related to the subject's visual experience, for otherwise, it could be held without her seeing anything, and hence, could be held without any connection to the shift in question. On the other hand, this supposed belief cannot be identical in content to the visual experience. For if it were, the shift would be a shift in the phenomenology of the visual experience itself, contra H2's assumption that the phenomenology underlying PC is non-sensory. What, then, could this belief be? What belief could, as $\mathrm{H} 2$ claims, accompany Mary's visual experience when she grasps, on the strength of her own visual experience, what her friends have encouraged her to grasp?

A possible answer might be that the alleged belief is inferred from visual experience. In the case at hand, e.g., it might be the inference that John and Jim share a certain set of visual properties, or that they share a certain configuration of visual properties, structural relations, etc., to the effect that John looks like Jim. PC is explained, on this reasoning, by the nonsensory phenomenology of realizing, through a certain inferential process, that A looks like B.

The problem with this answer is that we don't seem to consciously use inference, or apply criteria and algorithms, to detect visual resemblance. Even if this sort of putative cognitive processing is sometimes carried out at some level, the JVR in question is not made by consciously applying an inferential procedure. Aside from discerning certain properties that A shares with B (which, though necessary, is far from sufficient to prompt a JVR), there 
is no inferential procedure that we consciously follow to reach the conclusion that the object we are looking at visually resembles another object. In making the JVR that John looks like Jim, neither Mary nor her friends consciously individuate visual properties, make assessments of the number, structure, and interrelations of visual properties John shares with Jim, or carry out other high-level computations. Were use of such mechanisms common, debates about resemblance would presumably involve identifying errors in the application of such mechanisms. Yet in seeking to persuade someone that A looks like B, we rarely adduce any such errors. Rather, once we have pointed out the shared properties we have discerned, we wait for those who disagree with us to undergo a certain experience. In short, $\mathrm{H} 2$ cannot explain the non-sensory phenomenology underlying PC in terms of a belief acquired through the conscious application of an inferential procedure. JVRs ensue from visual experience in a more direct manner.

Similar problems arise if $\mathrm{H} 2$ is interpreted as claiming that E2 prompts a recollection of B. Assuming that recollection is not necessarily sensory (we will address a 'sensory' version of this claim below), it might be argued that the phenomenal shift in question is the shift from not recollecting B to recollecting B; in our case, it is the shift from Mary's not recollecting Jim, to her recollecting him. The problem with this claim is, again, that Mary remembers Jim very well before the shift, and this recollection strengthens when she is encouraged by her friends to notice John's visual resemblance to Jim. Nonetheless, Mary judges (at that initial stage) that John does not look like Jim. Recollection, therefore, cannot explain the phenomenal contrast between E1 and E2, for it may accompany both.

A general point about the recollection-JVR nexus is worth noting. Although making JVRs may involve recollection, recollection is by no means sufficient to prompt a JVR. Mary, e.g., might look at John and recall John's red Lamborghini, but this would not induce her to judge that John looks like a red Lamborghini. Of course, we do not deny that E2 (i.e., 
the JVR-prompting experience), but not E1, reminds Mary of Jim in some 'direct' manner. It is no coincidence that in making a JVR, the judging subject may say something like: "John, you remind me of your father: you look just like him." Yet the recollection—JVR nexus underscores the fact that $\mathrm{H} 2$ has not explained the difference between $\mathrm{E} 1$ and $\mathrm{E} 2$ by virtue of which E2 is able to 'directly' trigger a recollection of Jim. Moreover, the explanation of why $\mathrm{E} 2$, but not E1, 'directly' triggers a recollection of $\mathrm{B}$, must invoke a difference between the visual experiences E1 and E2 themselves, namely, a difference in sensory phenomenology, which is not an option for $\mathrm{H} 2$. (Note that our hypothesis, $\mathrm{H}$, can readily explain the difference: E2 directly triggers a recollection of Jim since it is a visual experience of Jim; i.e., the judging subject, knowing that Jim is not present, recollects Jim simply by virtue of visually experiencing him). But recollection in itself cannot account for PC.

To sum up, PC cannot be explained as a difference in non-sensory phenomenology (i.e., the phenomenology of non-sensory cognitive states such as thoughts, beliefs, or non-sensory recollections), hence $\mathrm{H} 2$ is not a satisfactory explanation of the phenomenal contrast between $\mathrm{E} 1$ and $\mathrm{E} 2$, let alone a better explanation than $\mathrm{H}$.

The last alternative hypothesis is $\mathrm{H} 3$ :

H3: E2 differs from E1 in representational content, though not with regard to the representation of $\mathrm{B}$.

$\mathrm{H} 3$ accepts that $\mathrm{PC}$ is sensory (specifically, visual), and that $\mathrm{PC}$ follows from a difference in representational content between E1 and E2, but asserts that the difference does not lie in the representation of B. Various versions of $\mathrm{H} 3$ can be formulated. On one version, the putative difference in representational content - the difference that explains $\mathrm{PC}-$ is in the properties that A is experienced as having: E2, but not E1, represents properties that A shares 
with B. According to this 'shared properties' version of H3, Mary, for instance, visually experiences John as having a combination of visual properties that he shares with Jim, and this experience (i.e., E2) induces her to judge that John visually resembles Jim. This account does not suggest that the subject consciously individuates visual properties, forms specific beliefs regarding the properties that A and B share, and by consciously applying some mode of inference, concludes that A looks like B - a suggestion that, as noted in our argument against $\mathrm{H} 2$, is highly implausible. Rather, it suggests that in judging visual resemblance, the subject visually experiences a set of properties that A shares with $\mathrm{B}$, and this visual experience prompts her to judge that A looks like B.

We grant that to make a JVR, it is necessary to visually experience a set of properties that A shares with B. As explained above (\$2), a judgment of visual similarity between A and B must be based on visual cues associated with B. However, we contend that making the JVR requires more than experiencing shared properties. For one thing, visually experiencing properties that A shares with B without being aware that the properties are shared would not prompt the subject to make a JVR. Moreover, even if the judging subject is fully aware that A and B have properties in common, she may nonetheless deny that A looks like B. There is nothing contradictory in claiming that, despite the properties that $\mathrm{A}$ and $\mathrm{B}$ have in common, A does not look like B. Recall that, following her friends' suggestions, Mary focuses on John's jawline, nose, and eyebrows, and affirms, on the basis of this visual experience, that they are identical in shape to Jim's jawline, nose, and eyebrows. Yet at this stage, Mary denies that John looks like Jim, stating that despite the shared jawline, nose, and brows, John simply doesn't look like Jim.

What, then, is it about Mary's subsequent visual experience (E2) that prompts her to affirm that John looks like Jim; what renders it sufficient to induce this JVR? There must be 
something intrinsic to E2 that links it to Jim more closely than the mere representation of shared properties would. We have suggested that this 'something' is an experience of Jim. Another problem with the 'shared properties' approach is that, ordinarily, even when the judgment is made that there is a visual resemblance between $\mathrm{A}$ and $\mathrm{B}, \mathrm{A}$ and $\mathrm{B}$ are also judged to differ in various respects. If, for instance, Mary is asked, pre-shift, why, having noticed the visual properties that John shares with Jim, she nonetheless believes that John does not look like Jim, she will straightforwardly point to the visual differences between them. Now Mary's friends may agree with her about those differences, but still argue that John does look like Jim. That is, although there is no disagreement between Mary and her friends regarding the shared / unshared visual properties, Mary's friends claim to 'see' something that Mary does not see. This disagreement can be straightforwardly explained by our proposed hypothesis $(\mathrm{H})$ : unlike Mary, her friends have already had their 'E2' experience, i.e., they have visually experienced the shared properties as properties of Jim. That is, E2, in addition to representing the properties shared by John and Jim, E2 represents Jim as having these properties. As explained in $\S 2$, this experience is entirely feasible despite the visual differences between John and Jim, since the shift in experience (from E1 to E2) is also a shift in the determinacy of the experienced properties: post-shift, the experienced properties, being indeterminate, are associated with Jim, hence Jim is represented in Mary's visual experience, prompting the JVR.

Supporters of (this version of) H3 might suggest that to be prompted to make the JVR, Mary and her friends need not experience Jim. Rather, they need only experience the set of indeterminate properties that are straightforwardly associated with Jim's appearance. However, the crucial question is not whether the said properties are generally associated with Jim, but how Mary and her friends come to associate them with Jim. Even if there is an algorithm that detects whether a set of (indeterminate or determinate) properties is associated 
with the appearance of a certain object, neither Mary nor her friends consciously apply it. Rather, they visually experience something that enables them to recognize that the set of properties they are experiencing is associated with Jim's appearance. What might this experience be? We contend that they visually experience Jim as having the properties in question, enabling them to realize that these properties are indeed associated with Jim.

Another version of $\mathrm{H} 3$ that could be put forward as an alternative to $\mathrm{H}$ might argue that PC ensues from the fact that E2, but not E1, involves a mental visual image of B. This might seem plausible, in particular, vis-à-vis sensory recollection, recollection that involves mental images. On this version of H3, when Mary has a visual experience of John, a visual image of Jim is generated, to the effect that her overall experience induces her to judge that John looks like Jim. ${ }^{11}$

Is this interpretation of $\mathrm{H} 3$ tenable? For one thing, it is implausible that when Mary initially cannot detect the resemblance, this is due solely to her not having summoned up an image of Jim. After all, when her friends encourage her to note the visual similarity, she can call up an image of Jim while looking at John, but nonetheless denies that John looks like Jim. Moreover, having an experience that combines a visual experience of John and a mental image of Jim by no means suffices to induce the JVR that John looks like Jim. For as pointed out regarding the recollection variant of $\mathrm{H} 2$, Mary could look at John and conjure up a mental

${ }^{11}$ It is generally accepted that images are often "projected or 'superimposed' on locations in a perceived scene," thus forming "hybrid experiences - involving both a bottom-up, perceptual component and a top-down, imaginative component" (Briscoe 2018, 162; "imaginative" here refers to mental images). See inter alia Briscoe (2011), Nanay (2010), Macpherson (2012), Kind (2018). For other types of imaginative penetration, see Chasid (2016); Chasid and Weksler (2020). 
visual image of John's Lamborghini, yet her 'hybrid' experience, a compound of the visual experience of John and the visual image of his car, would hardly induce her to judge that John looks like his car.

A somewhat similar account might invoke the idea that mental imagery can arise unintentionally, influencing perceptual experience without the subject's being aware of that influence. This idea is defended in various contexts, e.g., in Nanay's (2010) account of amodal perception, Macpherson's (2012) account of Delk and Fillenbaum's experiment, and explanations of cases where perceptual experience is 'completed' by imagery (see Briscoe 2018; Kind 2018). If mental images, in general, can tacitly influence perceptual experience and change its content, perhaps this is what occurs in the case of Mary's experiential shift. That is, it might be claimed that while Mary is looking at John, an image of Jim is unintentionally conjured up, 'penetrating' Mary's visual experience to the effect that, at least for a brief moment, the penetrated experience (i.e., E2) represents Jim, inducing Mary to judge that John looks like Jim.

However, this account of PC cannot, in fact, be regarded as a variant of $\mathrm{H} 3$, since it argues that, being penetrated by a mental image, E2 represents B, whereas $\mathrm{H} 3$ argues that E2 does not represent B. Whether or not this 'penetration' account can be successfully defended in general, or vis-à-vis JVRs in particular, it is certainly compatible with our explanation $(H)$. For its scope is limited to accounting for the generation of E2, and it accepts that the difference between E1 and E2 is that the former represents John whereas the latter represents Jim. The crucial point is that, once a visual experience of Jim is generated, Mary is induced to judge that John looks like Jim.

To summarize, variants of $\mathrm{H} 3$ are problematic in one way or another, and fail explain PC. The problems they raise underscore the advantages of $\mathrm{H}$, the hypothesis that the phenomenal contrast between an experience that does not induce a JVR, and an experience 
that does, ensues because the former represents A, whereas the latter represents B. We conclude that $\mathrm{H}$ is the best explanation of $\mathrm{PC}$.

\section{Conclusion}

We have defended the thesis that the visual experience that prompts someone looking at A to judge that A looks like B is a visual experience of B. We began by explaining this thesis, and discussing various assumptions it rests on. We argued that making the JVR in question requires awareness that one is looking at A. More importantly, we explained that although attentiveness to a set of A's properties that are associated with B's appearance is necessary for the JVR-prompting experience, i.e., the experience of B, this attentiveness is insufficient, since in addition to those shared properties, there may be manifest visual differences between A and B. We explained that in experiencing B by looking at A, it is often the case that some properties that $\mathrm{B}$ is experienced as having are indeterminate. This indeterminacy also explains why the visual experience of B that prompts the JVR differs phenomenally from ordinary visual experiences of B.

To argue for our thesis, we utilized the abductive method of phenomenal contrast. We showed that the phenomenal contrast between an experience that does not induce a JVR, and an experience that does, is best explained by the hypothesis that the latter represents B, whereas the former does not. Our account of the said phenomenal contrast, we demonstrated, is preferable to alternative accounts of that contrast, specifically, the non-representational difference account, non-sensory phenomenology accounts, and accounts based on representational differences other than those we argued for.

The proposed thesis can be further developed in several directions. First, our account focuses on explaining what prompts someone to judge that A looks like B in a specific type 
of case, namely, where the subject is looking at A and her visual experience prompts her, directly, to make the JVR that A looks like B. We do not claim that such JVRs are always made on the basis of a visual experience of B while looking at A, and acknowledge that they can ensue under other circumstances. It is possible, however, that at least some of these other sorts of cases can be explained in the spirit of our account. For instance, judgments of visual resemblance can obviously be made when both A and B are present: someone can view A and B simultaneously, and judge that they are visually similar. In such cases, even though the subject is looking at A and B simultaneously, what prompts the JVR is the realization that, in looking at A, the subject can fleetingly visually experience B. Such extensions of our thesis merit being examined separately.

A second direction for possible development of our account is the following. We discussed judgments of the form 'A looks like B.' Often, however, judgments of visual resemblance are made with respect to a certain kind of property; e.g., we say that A visually resembles B in color or in shape. Our account seems apt to explain such 'qualified' judgments: what induces the judgment that, e.g., A looks like B in color (shape), is that in looking at A, one visually experiences it as being the same color (shape) as B. Experiencing A as being the same color (shape) as B is possible even if A's color (shape) differs somewhat from B's: in such cases, B's color (shape) is represented in visual experience indeterminately (much as it may be represented indeterminately under abnormal viewing conditions - in the dark, when it's hazy outside, etc.). Developing this idea would require further examination of the relation between perceiving determinables and perceiving their determinates.

Our account can also be extended to judgments of resemblance with respect to other perceptual modalities. For instance, in hearing A, we may be prompted by our auditory experience to judge that A sounds like B. Reasoning along the lines of our account of JVRs, we might conjecture that judgments of auditory resemblance are prompted by specific 
auditory experiences: when hearing A, we fleetingly have an auditory experience of B. Clearly, the possibility of hearing A and having an auditory experience of B would require further analysis, especially in cases where, despite the auditory similarity, there are auditory differences between A and B. It seems likely that our idea that there is a shift from experiencing determinate visual properties associated with A to experiencing indeterminate visual properties associated with B can be developed to explain judgments of auditory resemblance as well.

Thirdly, the question of whether judgments of visual resemblance are true or false, or whether there is a standard of correctness that applies to such judgments, has not been addressed in this paper. Is there a subject-independent fact that renders JVRs true (false)? Pre-theoretical intuitions as to whether visual resemblance is 'objective' in any sense seem inconclusive. It could be claimed, as Goodman (1972) did in critiquing resemblance in general, that if 'similarity' denotes shared properties, then it "functions as little more than a blank to be filled" (445). On this view, the 'objective' criterion for determining whether object A resembles object B is whether A and B share the properties denoted by a specific instance of 'resembles.' Yet given that a judgment of visual resemblance amounts to more than just an acknowledgment of shared properties, what subject-independent fact is it that renders the judgment true?

Our account may suggest an answer. At first sight, it does not assume a subjectindependent relation or property of visual resemblance: recognizing visual resemblance is a matter of having a certain type of visual experience. In a sense, in taking the relevant standard of correctness to be grounded in having a certain type of experience, our account seems akin to various Humean accounts of aesthetic judgment. Looking at A and experiencing B may, however, ensue from the fact that A and B share specific kinds of properties (or combinations thereof), by virtue of which an experience of one is generated by 
looking at the other. If this suggestion is correct, then visual resemblance may be more 'objective' than our account seems to imply. Investigating this question would likely require empirical input. This paper, though, focused on the conscious, personal level. At this level, judgments of visual resemblance reflect the capacity to visually experience object B by looking at object $\mathrm{A}$, and thus to judge that A visually resembles $\mathrm{B}$.

Acknowledgments: An early version of this paper was presented at a workshop on picture perception and depiction at the Centre for Philosophical Psychology, the University of Antwerp. Many thanks to Bence Nanay, John Kulvicki, Alberto Voltolini, John Zeimbekis, and other participants of the workshop for their helpful comments. Special thanks to Michalle Gal, Anna Ichino and Arnon Levy for illuminating discussions and comments. We also thank two anonymous referees for their insightful comments. This research was supported by the Israel Science Foundation, grants No. 939/16 and 1544/20.

\section{References}

Armstrong, David M. (1978). A Theory of Universals: Universals and Scientific Realism (Volume II). Cambridge: Cambridge UP.

Blumson, Ben (2017). “Two Conceptions of Similarity,” Philosophical Quarterly 68 (270):21-37.

Briscoe, Robert (2011). "Mental Imagery and the Varieties of Amodal Perception. Pacific Philosophical Quarterly 92 (2):153-173.

Briscoe, Robert (2018). “Superimposed Mental Imagery: On the Uses of Make-Perceive,” In Fiona Macpherson \& Fabian Dorsch (eds.), Perceptual Imagination and Perceptual Memory, 161-185. 
Chasid, Alon (2016). "Imaginatively-Colored Perception: Walton on Pictorial Experience," Southern Journal of Philosophy, 54 (1):27-47.

Chasid, Alon \& Weksler, Assaf (2020), "Belief-like Imaginings and Perceptual (Non)Assertoricity," Philosophical Psychology, 33 (5):731-751.

Chudnoff, Elijah (2015). "Phenomenal Contrast Arguments for Cognitive Phenomenology," Philosophy and Phenomenological Research 91(1):82-104.

Crane, Tim and French, Craig (2017). "The Problem of Perception,” in: Edward N. Zalta (ed.), The Stanford Encyclopedia of Philosophy, URL= <https://plato.stanford.edu/archives/spr2017/entries/perception-problem/>.

Fish, William (2010). Philosophy of Perception: A Contemporary Introduction. New York: Routledge.

Goodman, Nelson (1972). "Seven strictures on similarity," in N. Goodman (ed.), Problems and Projects. Indianapolis: Bobbs-Merrill, 23-32.

Harman, Gilbert (1990). “The Intrinsic Quality of Experience,” Philosophical Perspectives $4: 31-52$

Helton, Grace (2016). “Recent Issues in High-Level Perception,” Philosophical Compass 11:851-62.

Hopkins, Robert (1998). Picture, Image and Experience: A Philosophical Inquiry, Cambridge: Cambridge UP.

Hyman, John and Bantinaki, Katerina (2017). "Depiction," in The Stanford Encyclopedia of Philosophy, Edward N. Zalta (ed.), URL = <https://plato.stanford.edu/archives/sum2017/entries/depiction/>.

Kind, Amy (2018). “Imaginative Presence,” in F. Dorsch and F. Macpherson, Phenomenal Presence. New York: Oxford UP, 165-180.

Kulvicki, John (2014). Images. New Yok: Routledge. 
Koksvik, Ole (2015). "Phenomenal Contrast: A critique," American Philosophical Quarterly 52(4):321-34.

Macpherson, Fiona (2012). “Cognitive Penetration of Colour Experience: Rethinking the Issue in Light of an Indirect Mechanism." Philosophy and Phenomenological Research 84 (1):24-62.

Macpherson, Fiona (2014). "Is the Sense-Data Theory a Representationalist Theory?" Ratio 27 (4):369-392.

McGinn, Colin (1982). The Character of Mind. Oxford: Oxford UP.

Nanay, Bence (2010). "Perception and Imagination: Amodal Perception as Mental Imagery.” Philosophical Studies 150 (2):239-254.

Nanay, Bence (2011). “Do We See Apples as Edible?” Pacific Philosophical Quarterly $92(3): 305-22$.

Siegel, Susanna (2006). "Which Properties Are Represented in Perception?” in Tamar S. Gendler and John Hawthorne (eds.), Perceptual Experience. Oxford: Oxford UP, 481503.

Siegel, Susanna (2007). "How Can We Discover the Contents of Experience?" Southern Journal of Philosophy 45(S1):127-42.

Siegel, Susanna (2010). The Contents of Visual Experience. Oxford: Oxford UP.

Siegel, Susanna (2016). "The Contents of Perception," in Edward N. Zalta (ed.), The Stanford Encyclopedia of Philosophy, URL = <https://plato.stanford.edu/archives/win2016/entries/perception-contents/>.

Siewert, Charles (1998). The Significance of Consciousness. Princeton: Princeton UP. Tye, Michael. (2002). "Representationalism and the Transparency of Experience,” Noûs 36(1):137-51. 
Tye, Michael (2009). "The Admissible Contents of Visual Experience," Philosophical Quarterly 59 (236):541-62.

Walton, Kendall L. (2008). Marvelous Images. New York: Oxford UP. 